\title{
Metabolic Alterations in Rat Somatosensory Cortex Following Unilateral Vibrissal Removal ${ }^{1}$
}

\author{
W. DALTON DIETRICH, ${ }^{\prime 2}{ }^{2}$ MYRON D. GINSBERG, ${ }^{\star}$ RAUL BUSTO, ${ }^{\star}$ AND DAVID W. SMITH*
}

*Cerebral Vascular Disease Research Center, Departments of Neurology, and $¥$ Anatomy and Cell Biology, University of Miami School of Medicine, Miami, Florida 33101

\begin{abstract}
Local cerebral metabolic rates for glucose were studied

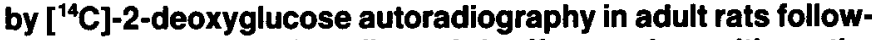
ing acute and chronic unilateral deafferentation, with particular attention to the barrel field regions of the primary somatosensory cortex. Deafferentation was produced by permanently removing all of the large whiskers (vibrissae) on one side of the face. Data from experimental animals were then compared to data from sham-operated controls at 1,5 , $10,15,30$, and 60 days after deafferentation. The rate of glucose utilization was maximally depressed at day 1 in the deafferented barrel field. After that, there was a progressive recovery of glucose utilization toward control levels at each subsequent time point. In contrast, glucose utilization in the barrel field associated with the intact set of whiskers increased by day 5 and remained elevated throughout the duration of the experiment. Similar patterns of altered cerebral metabolism were observed following unilateral infraorbital nerve transection. These results demonstrate that interference with normal somatosensory input causes a transient decrease in glucose metabolism of the contralateral cortical barrel-field and, in addition, causes long-term Increments in glucose metabolism in the ipsilateral cortical barrel field-a structure not normally influenced by acute manipulation.
\end{abstract}

The $\left[{ }^{14} \mathrm{C}\right]-2$-deoxyglucose (2-DG) method, established by Sokoloff et al. (1977), has revealed the central nervous system to be functionally heterogeneous and capable of adjusting its metabolism according to functional demands (for reviews, see Hand, 1981; Sokoloff, 1981). One experimental strategy which has clearly demonstrated a close coupling between local cerebral activity and glucose consumption has been the study of short-term effects of sensory deprivation on specific neuronal circuits. In the auditory (Sokoloff, 1977), olfactory (Sharp et al., 1975; Skeen, 1977), and visual systems (Sokoloff, 1975; Kennedy et al., 1976; Hubel et al., 1978), acute deprivation combined with the 2-DG technique has

Received April 2, 1984; Revised Scptember 4, 1984;

Accepted September 28, 1984

\footnotetext{
${ }^{1}$ This work was supported by United States Public Health Service Grant NS 05820-18. W. D. D. is an Established Investigator of the American Heart Association. We wish to thank Drs. Thomas A. Woolsey and Sami I. Harik for their comments and criticisms of the manuscript, Ofelia Alonso, Mayra Gonza-Carvajal, and Isabel Valdes for technical assistance, and Helen Valkowitz for typing.

${ }^{2}$ To whom correspondence should be addressed, at Department of Neurology (D4-5). University of Miami School of Medicine, P. O. Box 016960, Miami, FL 33101 .
}

provided information concerning the functional organization of these circuits.

In rats and certain other rodents, there is an isomorphic relationship between the organization of the large facial whiskers and anatomically distinct units within the primary somatosensory cortex (Sml) (Woolsey and Van der Loos, 1970; Woolsey, 1978). Sensory input from the large whiskers (mystacial vibrissae) projects to the contralateral cortex through three synapses-in the ipsilateral trigeminal nuclei (Belford and Killackey, 1979), in the contralateral ventrobasal thalamus (Van der Loos, 1976), and in the contralateral Sml. There, cell bodies in lamina IV are arranged in cytoarchitectonic units called "barrels," within the posteromedial barrel subfield (PMBSF). The PMBSF has been shown anatomically (Van der Loos and Woolsey, 1973; Weller and Johnson, 1975), physiologically (Welker, 1971), and biochemically (Wong-Riley and Welt, 1980; Dietrich et al., 1981) to be functionally related to similarly arranged whiskers on the contralateral face. Consequently, the accessibility of these peripheral organs to various types of manipulations has prompted the use of this neuronal circuit to study acute and chronic effects of sensory deprivation and deafferentation. Durham and Woolsey (1978) applied the 2-DG method to assay regional activity in the barrel subfield after acute removal of selective whiskers in mice. Autoradiograms demonstrated decreased metabolic activity within barrels associated with the whiskers that were clipped 1 day earlier, thus suggesting that the presence of the whiskers was required to drive the cortical neurons in the behaving animal.

In contrast to short-term alterations following whisker removal, chronic removal of vibrissae results in changes in certain enzymes associated with energy metabolism. Wong-Riley and Welt (1980), studying the mouse somatosensory cortex, demonstrated a decrease in the level of the mitochondrial enzyme cytochrome oxidase within appropriate barrels 80 days after whisker cauterization. Studies using quantitative microchemical techniques have extended these findings by documenting the time course of changes for a number of glycolytic and mitochondrial enzymes following the removal of whiskers (Dietrich et al., 1981). Also, chronic sensory deprivation produced by clipping all of the large whiskers on one side of the face has been shown recently to result in significant changes in the levels of certain enzymes (Dietrich et al., 1982). Surprisingly, enzyme levels in barrels associated with intact whiskers increased. When the whiskers were allowed to grow, thereby reversing sensory deprivation, enzyme levels returned to normal. One possible explanation of these results involves increased utilization of the intact whiskers and increased metabolism of the corresponding barrel field.

The present study was undertaken to assess: (1) the acute and chronic effects of complete unilateral whisker removal on glucose metabolism within the deafferented barrel field; (2) whether unilateral deafferentation results in metabolic changes within the barrel field associated with intact whiskers; and (3) whether a relationship exists 
between these metabolic alterations and the previously documented enzymatic response to this experimental paradigm.

\section{Materials and Methods}

Animal preparation. Forty-six adult male Wistar rats were used. In 27 rats, all of the large whiskers on one side of the face were first plucked and their corresponding hair follicles were cauterized under Halothane anesthesia with the aid of a dissecting microscope. To control for possible hemispheric asymmetries, the side of the face on which the whiskers were removed was alternated. Rats were allowed to recover for $1,5,10,15,30$, or 60 days after operation. Facial pads were examined grossly to verify the absence of whiskers prior to the 2-DG experiments. Sham-operated controls, 30 or 90 days of age, underwent all surgical procedures except for whisker removal. In six additional rats, the infraorbital branch of the trigeminal nerve, which innervates the whisker pads, was surgically isolated unilaterally with the aid of a dissecting microscope and tightly ligated just distal to the infraorbital foramen. To prevent regeneration, a $1-\mathrm{mm}$ segment of the nerve distal to the ligature was removed. These rats were allowed to recover for 1 and 30 days. Following the 2-DG experiment, the proximal stump of the cut nerve was examined in each animal to determine signs of regrowth

On the day of the experiment, rats were briefly anesthetized with Halothane for the insertion of arterial and venous catheters, and were restrained in a plaster body-cast. They were then allowed to recover from the effects of anesthesia and surgery for at least $2 \mathrm{hr}$. In preliminary experiments, the precise location of the barrel subfield in 2-DG autoradiograms of coronally sectioned brain was documented utilizing the method of Hand et al. (1977). In brief, all of the large whiskers on one side of the face of three rats were first clipped to equal lengths and then stroked 2 to 3 times/sec with a handheld brush for $5 \mathrm{~min}$ before and $40 \mathrm{~min}$ following a pulse injection of $\left[{ }^{14} \mathrm{C}\right]-2$ DG.

To determine whether the metabolic responsiveness of the PMBSF ipsilateral to chronic deafferentation differed from that of controls, the following experiment was carried out. Three rats had all of their vibrissae plucked and their follicles cauterized as previously described. These animals were then allowed to recover for 30 days, at which time the remaining set of whiskers was stimulated and the 2-DG procedure was carried out. Levels of local cerebral metabolic rate for glucose (ICMRglu) within both the stimulated and nonstimulated PMBSFs were then compared to those values obtained from three control rats.

2-DG method. Approximately $20 \mu \mathrm{Ci}$ of $\left[{ }^{14} \mathrm{C}\right]-2-\mathrm{DG}$ (New England Nuclear) dissolved in isotonic saline were rapidly injected intravenousty. Arterial blood samples were withdrawn at frequent intervals, and plasma aliquots of the samples were assayed for their radioactive content by liquid scintillation counting and for their glucose content by means of an automated glucose analyzer (Beckman). Forty-five minutes after the injection of 2-DG, the rats were killed by injection of $\mathrm{KCl}$. The brains were quickly removed and frozen in Freon-22 at $-50^{\circ} \mathrm{C}$. The brains were later warmed to $-20^{\circ} \mathrm{C}$ and sectioned in a cryostat. Coronal sections, $20 \mu \mathrm{m}$ thick, together with ${ }^{14} \mathrm{C}$-methacylate standards (Amersham) were exposed to Kodak SB-5 x-ray film for 10 days. The resulting autoradiograms were digitized on a rotating-drum scanning densitometer (Optronics) interfaced with a PDP 11/44 minicomputer which displayed and quantitated ICMRglu. Region-of-interest analysis was carried out by means of a square cursor of user-definable size placed over the region of lamina IV. Lamina IV was initially identified anatomically by histologically examining the same cryostat section which had produced the 2-DG autoradiogram. Multiple readings were obtained from both the ipsilateral and contralateral barrel fields of each experimental animal as well as from controls. In addition, ICMRglu readings were made of entire brain sections previously selected for lamina IV analysis. Ratios were obtained for each animal by dividing ICMRglu of lamina IV by the mean ICMRglu of the corresponding entire brain section; these were designated as "normalized ICMRglu."

Data were analyzed by one- or two-way analysis of variance, and statistical significance was assessed by Dunn's multiple comparison procedure and by Scheffe's $S$ test (Kirk, 1982).

\section{Results}

Localization of barrel fields. Forty-five minutes of whisker stimulation resulted in focal increases in glucose utilization within the PMBSF of the contralateral Sml cortex (Fig. 1A). Increased labeling was prominent on serial coronal sections taken between the levels of mid-striatum and dorsal hippocampus. Computer-processed 2DG autoradiograms consistently demonstrated increased labeling extending in this region from lamina I down to the superficial half of lamina Vl, with the largest increase in ICMRglu occurring over lamina
IV (158\% of control). In addition to increased glucose utilization in the contralateral barrel field, unilateral whisker stimulation also resulted in increased labeling bilaterally in cortical regions lateral to and separated from the PMBSF (Fig. 1A). These focal regions were most pronounced at the level of the dorsal hippocampus and appeared to represent the somatotopic representation of the facial region within the Smll cortex (Welker, 1971).

Control rats. Cerebral metabolic rates for glucose in the region of the PMBSF were determined in four 30-day-old and three 90-day-old sham-operated animals. Values in these age groups did not vary significantly, nor were there consistent differences between right and left PMBSFs. Quantitative analysis of autoradiograms consis tently verified that lamina IV had the highest level of resting metabolic rate when compared to the other laminae with ICMRglu (mg/100 $\mathrm{gm} / \mathrm{min}$ ), being $10.04 \pm 1.59$ (SD). Rates of glucose utilization were consistent with those values reported by others utilizing Wistar rats (Ingvar and Siesjö, 1982; Pulsinelli et al., 1982) but were lower than published values obtained from Sprague-Dawley rats (McCulloch et al., 1979; Smith et al., 1980).

Experimental rats. Local brain glucose utilization was affected in both the ipsilateral and contralateral PMBSFs following unilateral whisker removal (Table I). In the deafferented barrel field, glucose utilization decreased to $82 \%$ of control at 1 day post-whisker removal. The band of high glucose utilization in lamina IV which was consistently identified in controls (Fig. $1 B$ ) was virtually absent in the deafferented barrel field at this time period (Fig. 1C). Glucose utilization also decreased to a lesser degree in other cortical layers $(90 \%$ of control). Within 5 days after whisker removal, recovery of ICMRglu was documented within the deafferented PMBSF (Table I).

In contrast to the transient hypometabolic response demonstrated in the deafferented barrel field, glucose metabolism in the ipsilateral barrel field increased over time in response to unilateral whisker removal. Due to animal variability, statistical differences between control values and values obtained from experimental animals could only be demonstrated at 30 days (Table I). Normalized ICMRglu, determined by dividing lamina IV ICMRglu values by the mean glucose metabolic rate obtained from the entire section, decreased the degree of variability between animals. As shown in Figure 2, this method of data analysis allowed significant differences to be demonstrated between control and several experimental groups, as well as in interhemispheric comparisons of individual experimental groups. As early as day 5 , glucose utilization was shown to be elevated over control levels and remained so for the duration of the experiment.

A similar trend was observed in rats which underwent unilateral nerve transection (Table II). After 1 day, glucose utilization in lamina IV of the deafferented barrel field was depressed by $15 \%$ as compared to the opposite barrel field. Although ICMRglu was bilaterally elevated when compared to the day 1 whisker-removed rats (Table I), normalized ICMRglu values were similar (Fig. 2). At 30 days, there was no difference between the metabolic response to whisker damage and nerve transection. Glucose utilization within lamina IV of the opposite barrel field was increased $29 \%$ as compared to the contralateral deprived barrel field. Examination of the cut nerves after 2-DG study showed no evidence of peripheral regeneration. Additionally, the ligatures which had been placed proximal to the point of nerve transection were still in place.

A significant increase in ICMRglu within the contralateral PMBSF was documented in both control and chronically deafferented rats following unilateral whisker stimulation (Table III). Although ICMRglu contralateral to whisker stimulation was higher in the deafferented than in the control rats, this difference did not attain statistical significance. Additionally, normalized ICMRglu within the stimulated PMBSF of deafferented rats was significantly different from the ipsilateral PMBSF, whereas no significant difference between normalized values from stimulated control rats was shown. 

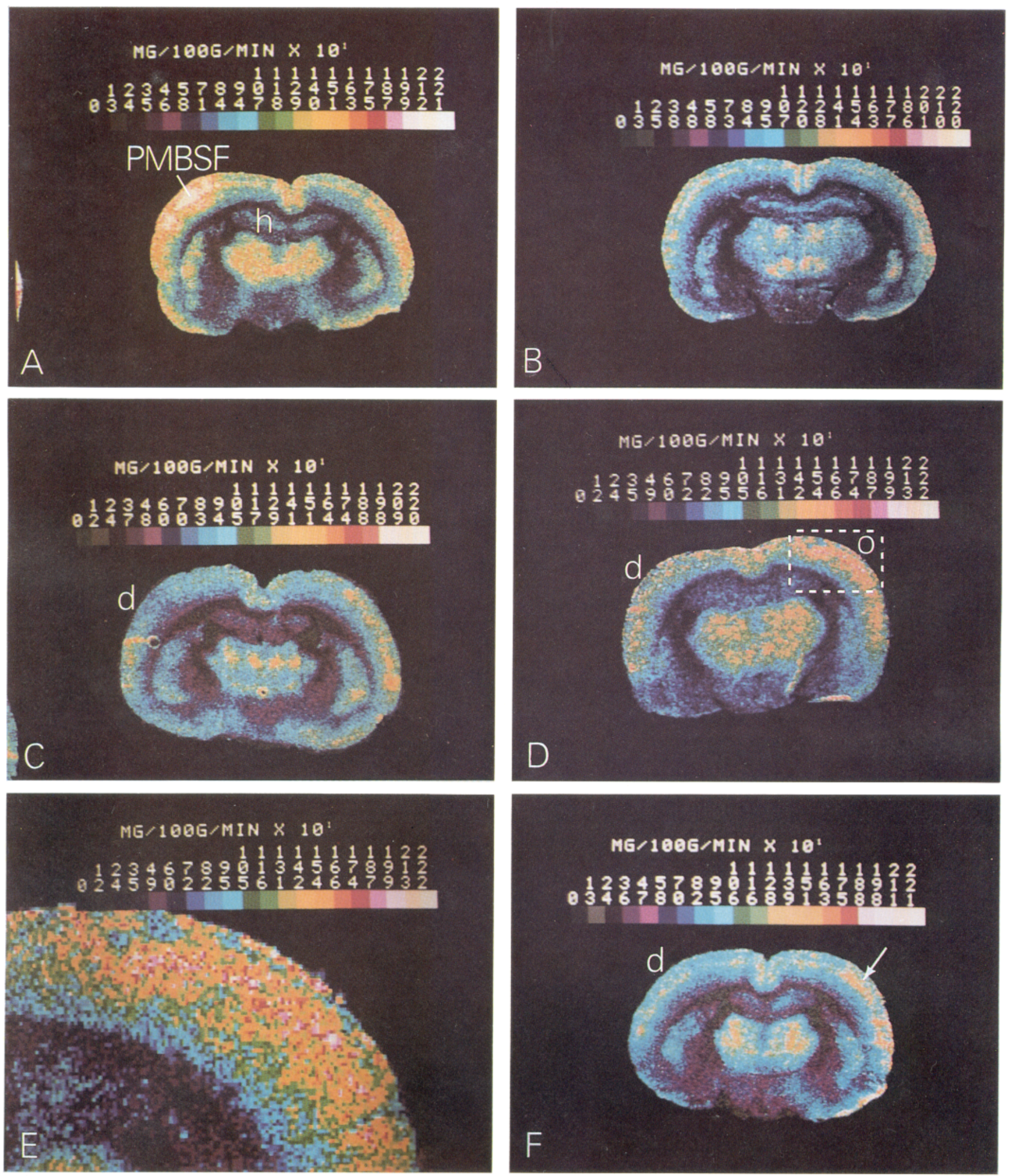

Figure 1. Computer-assisted $\left[{ }^{14} \mathrm{C}\right]-2-\mathrm{DG}$ autoradiograms of coronally sectioned rat brain. The color spectrum on the top of each pane/ represents different rates of glucose utilization in $\mathrm{mg} / 100 \mathrm{gm} / \mathrm{min} \times 10$. A, Unilateral whisker stimulation results in a focal increase in glucose utilization within the region of the contralateral PMBSF. This experimental manipulation allowed for the precise localization of the PMBSF within brain sections taken between the levels of the striatum and dorsal hippocampus $(h) . B$, Control animal. Within the cerebral cortex the area corresponding to lamina IV is evident as a band of high glucose utilization relative to the rest of the cortex. $C$, Twenty-four hours after unilateral whisker removal, glucose utilization in the deprived PMBSF (d) is depressed. Note the absence of a band of high glucose utilization over lamina IV. D. Following 5 days, glucose utilization has begun to return to control levels in the deprived $(d)$ PMBSF but is elevated in the opposite barrel field $(0)$. E. High magnification of the area outlined in $D$ demonstrating several focal areas of hypermetabolism overlying lamina IV. F. Following 60 days, hypermetabolism is still apparent in the region of the ipsilateral PMBSF ( $\uparrow$ ). In contrast, glucose utilization is normal over lamina IV in the contralateral, deprived $(d)$ PMBSF. Note the presence of the band of high glucose utilization overlying lamina IV. 
TABLE I

Cerebral metabolic rates for glucose in lamina $N$ of the barrel field

Glucose Utilization (mg/100 gm/min)

\begin{tabular}{|c|c|c|c|c|c|c|c|}
\hline & \multirow{2}{*}{$\begin{array}{c}\text { Sham- } \\
\text { Operated } \\
\text { Controis }^{2} \\
(n=7)\end{array}$} & \multicolumn{6}{|c|}{ Experimental Groups (days after damage) } \\
\hline & & $\left(\begin{array}{c}1 \\
=3\end{array}\right)$ & $\left(\begin{array}{c}5 \\
=\end{array}\right)$ & $\begin{array}{c}10 \\
(n=4)\end{array}$ & $\begin{array}{c}15 \\
(n=4)\end{array}$ & $\begin{array}{c}30 \\
(n=7)\end{array}$ & $\begin{array}{c}60 \\
(n=5)\end{array}$ \\
\hline Deprived PMBSF & $\pm 1.69^{\circ}$ & \pm 1.82 & \pm 2.42 & \pm 1.44 & \pm 1.97 & \pm 1.01 & \pm 3.94 \\
\hline \multirow[t]{2}{*}{ Opposite PMBSF } & 10.03 & 11.15 & 12.53 & 12.20 & 13.28 & $15.19^{\circ}$ & 13.27 \\
\hline & \pm 1.52 & \pm 1.08 & \pm 2.73 & \pm 1.11 & \pm 1.36 & \pm 1.12 & \pm 3.11 \\
\hline Deprived/Opposite & 1.00 & $0.74^{d}$ & $0.75^{a}$ & $0.81^{\circ}$ & $0.73^{d}$ & $0.79^{d}$ & $0.83^{\sigma}$ \\
\hline
\end{tabular}

${ }^{a}$ Values for sham-operated controls were taken from left and right barrel fields.

${ }^{b}$ Each number represents the mean \pm SD.

'Differs from control, $p<0.01$, two-way analysis of variance (Dunn's test).

${ }^{\sigma}$ Differs from control, $p<0.01$, one-way analysis or variance (Dunn's test).

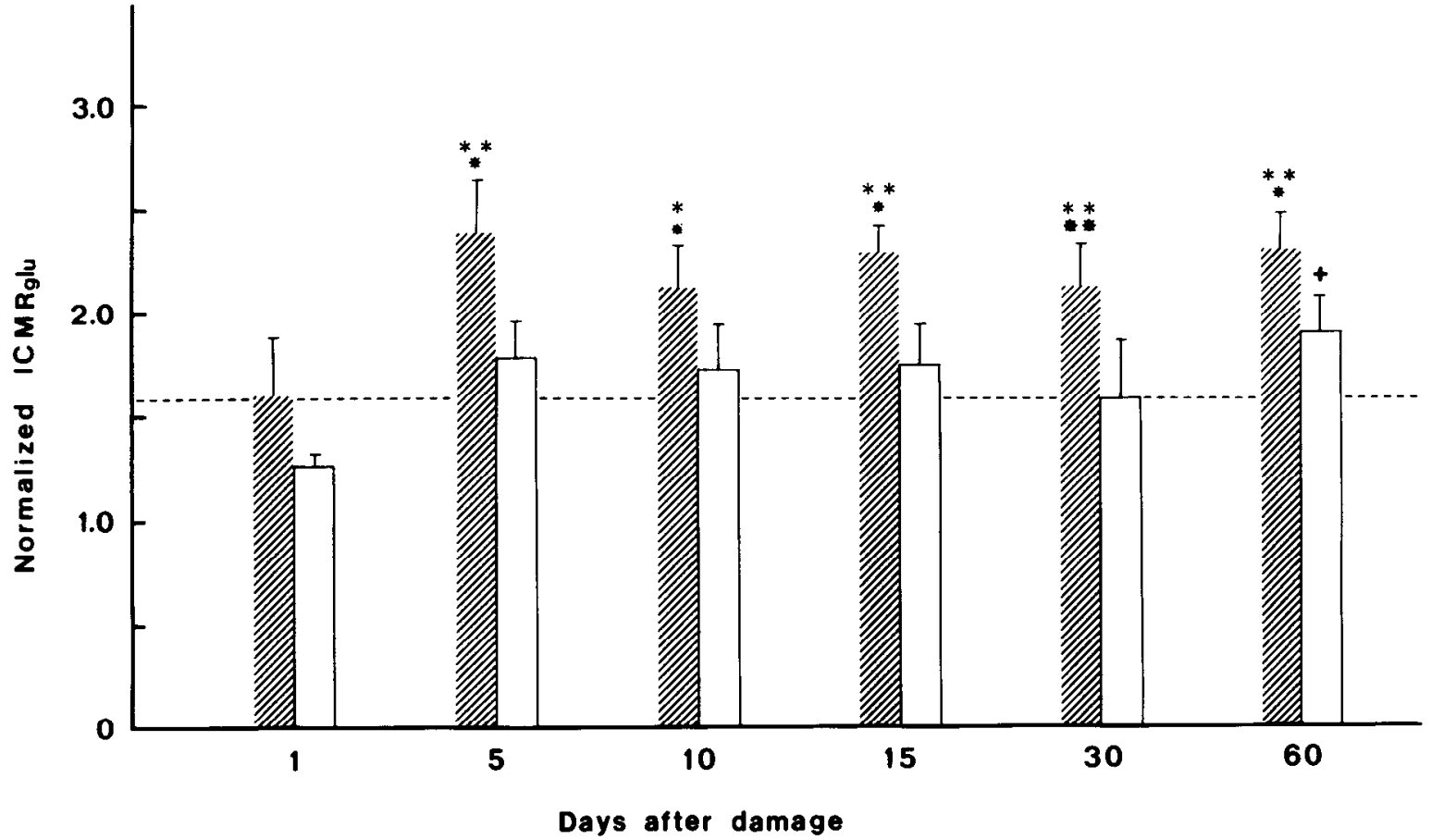

Figure 2. Effect of unilateral whisker removal on normalized, local cerebral metabolic rates for glucose (ICMRglu) within ipsilateral (hatched bars) and contralateral (open bars) barrel fields. The horizontal dashed line indicates the mean value of normalized ICMRglu obtained trom age-matched shamoperated controls. Time after whisker cauterization is depicted on the abscissa. Each data point represents the mean \pm SD of three to seven animals. Asterisks indicate significance of difference as follows: significantly different from sham-operated control, $* *(p<0.01), *(p<0.05)$, significantly different from contralateral deprived barrel field, $* *(p<0.01), * 0.05$; significantly different from 1-day deprived barrel field, $+(p<0.01)$; two-way analysis of variance (Dunn's test or Scheffe's test).

\section{Discussion}

The present study continues previous investigations into the effects of deafferentation on the adult rodent Sml cortex (Dietrich et al., 1981, 1982). The principal findings are that permanent removal of all of the large whiskers unilaterally results in an initial decrease in glucose utilization with subsequent recovery in the contralateral barrel field. In the ipsilateral barrel field associated with the intact whiskers, glucose utilization increased over control levels and remained elevated for the duration of the experiment. This bilateral response is in contrast to both electrophysiological and 2-DG data obtained in this study and others demonstrating that the Sml cortex responds acutely only to stimulation of the contralateral body surface (Welker, 1971; Hand et al., 1977). It is therefore apparent that unilateral chronic deafferentation of a rather large cortical representation induces compensatory and adaptive changes in the adult rat brain. Previous evidence for changes taking place in the adult somatosensory cortex has been recently summarized (Hand, 1982; Kaas et al., 1983).

The recovery pattern of glucose utilization documented in the present study may be similar to that observed when electrophysiological methods are used to study the effects of sensory deprivation. For example, in cortical areas devoted to hand representation (Merzenich et al., 1983a), microelectrode mapping procedures demonstrate that median nerve transection does not permanently result in a silent or chronically unresponsive cortical region. Rather, new patterns of activation are observed over time, which result from the expansion of bordering skin surfaces into the former median neve cortical representation zone (Merzenich et al., 1983b). Other recent data provided by Wall and Cusick (1984) have demonstrated a rapid time course of input substitution following sciatic nerve transection in the rat, again implicating the capacity for cortical reorganization after nerve injury. These electrophysiological results are entirely 
TABLE ॥

Effects of infraorbital nerve transection upon glucose utilization $(\mathrm{mg} / 100$ $\mathrm{gm} / \mathrm{min}$ ) in lamina $\mathrm{N}$ of the barrel field

\begin{tabular}{lcc}
\hline & \multicolumn{2}{c}{ Days after Damage } \\
\cline { 2 - 3 } & \multicolumn{1}{c}{$\begin{array}{c}1 \\
(n=3)\end{array}$} & $(n=3)$ \\
\hline Deprived PMBSF & & \\
ICMRglu & $13.26 \pm 0.52^{a, b}$ & $11.83 \pm 0.97^{c}$ \\
Normalized ICMRglu & $1.36 \pm 0.07$ & $1.80 \pm 0.27^{b}$ \\
Opposite PMBSF & & \\
ICMRglu & $15.76 \pm 0.30$ & $15.24 \pm 0.92$ \\
Normalized ICMRglu & $1.59 \pm 0.10$ & $2.31 \pm 0.16$
\end{tabular}

${ }^{a}$ Each number represents the mean \pm SD.

${ }^{b}$ Differs from opposite barrel field $(\rho<0.05)$

${ }^{c}$ Differs from opposite barrel field $(\rho<0.01)$.

TABLE III

Local cerebral glucose utilization ( $\mathrm{mg} / 100 \mathrm{gm} / \mathrm{min}$ ) within lamina $\mathrm{N}$ of the PMBSF following unilateral whisker stimulation

\begin{tabular}{lcc}
\hline \multirow{2}{*}{ Animal } & \multicolumn{2}{c}{ Barrel Fields $^{a}$} \\
\cline { 2 - 3 } & \multicolumn{1}{c}{ Ipsilateral } & Contralateral \\
\hline Control $(n=3)$ & $11.75 \pm 2.70^{\circ}$ & $18.37 \pm 3.20^{\circ}$ \\
ICMRglu & $1.61 \pm 0.20$ & $2.30 \pm 0.42$ \\
$\quad$ Normalized ICMRglu & & \\
Thirty-day unilateral deafferen- & & \\
$\quad$ tation $(n=3)$ & $13.33 \pm 1.04$ & $23.06 \pm 2.70^{\circ}$ \\
ICMRglu & $1.46 \pm 0.19$ & $2.52 \pm 0.32^{\circ}$ \\
Normalized ICMRglu &
\end{tabular}

\footnotetext{
${ }^{a}$ In relationship to the set of stimulated whiskers.

${ }^{b}$ Values are means \pm SD.

${ }^{c}$ Differs from opposite barrel field $(\rho<0.05)$.

${ }^{a}$ Differs from opposite barrel field $(p<0.01)$.
}

consistent with the present findings. The 2-DG method allows for the anatomical visualization of variations in neuronal activity and makes it possible to map functional pathways polysynaptically (Kennedy et al., 1975). The initial decrease and subsequent normalization observed in the present study would suggest that this cortical region over time became activated as a result of some form of reorganization phenomenon.

The present study addresses the question of whether the proposed reorganization occurred within the central nervous system or was the result of a peripheral response. Waite and Taylor (1978) reported that, following whisker cauterization in adult rats, regeneration of the damaged peripheral nerve fibers resulted in reinnervation to regions of skin surrounding the damaged area. To clarify this point, a section of the infraorbital branch of the maxillary division of the trigeminal nerve, which innervates the vibrissae and runs just beneath the skin, was transected and ligated to inhibit the potential for reinnervation. Following 1 day, the pattern of normalized ICMRglu within both the deafferented and opposite barrel fields was similar to that obtained following whisker removal. The elevated levels of ICMRglu observed bilaterally at this time period following nerve transection most likcly rosulted from postsurgical stress. Carlsson et al. (1975) have shown that stressful situations can cause dramatic increases in cerebral metabolism. There were no differences in cortical glucose metabolism between nerve transection and whisker damage at day 30 , and peripheral regeneration in the area of the proximal stump was not apparent. Therefore, although a minor role for peripheral nerve regeneration cannot be completely discounted, the present cortical alterations appear to be the result of adaptive processes occurring within the central nervous system. The exact site of these adaptive changes requires further investigation.

The time course and characteristics of the metabolic changes demonstrated in the present study may reflect the influences of several possible mechanisms. The early normalization of glucose utilization within the deafferented barrel field might suggest the unmasking of previously ineffective synapses (Wall, 1977; Merrill and Wall, 1978; Kaas et al., 1983). These types of synapses, thought not to be functional while the main input to the region is present, may become responsive when this input is removed. There exists within the cerebral cortex the circuitry for horizontal interactions between primary projection areas and neighboring cortical fields (Jones and Powell, 1969; Friedman et al., 1980). Whether or not chronic removal of the ventrobasal thalamic input to the vibrissal cortical representational zone results in the switching of inputs and increased communication between neighboring cortical regions remains to be determined.

The finding of increased glucose metabolism in the ipsilateral barrel field in response to deafferentation of the contralateral homonymous area is a previously unreported phenomenon. It should be emphasized that this response was obtained in restrained, awake rats following complete unilateral whisker removal. During the time period between whisker removal and 2-DG study, animals were allowed to explore their cages freely. One possible mechanism for this hypermetabolism comes from behavioral studies demonstrating the rat's dependence on these tactile organs for furnishing guiding sensations (Vincent, 1912; Welker, 1964). Therefore, if one set of whiskers were removed unilaterally, an increased dependence on the contralateral intact set might result. Vincent (1912) noted that, during maze-running, rats with unilaterally clipped whiskers stayed close to the maze edge on the side of the intact whiskers as if they were using their one set of whiskers to run the maze, whereas normal rats seemed to oscillate from one edge of the maze to the other.

Another interpretation hypothesizes that the hypermetabolic state of the ipsilateral barrel field resulted directly from deafferentation. Figure 3 summarizes the relationship between the cerebral metabolic rate in the contralateral and ipsilateral PMBSFs following deafferentation. For each of the six time points studied, a linear relationship exists between the two PMBSFs. This consistent relationship over time might indicate that the alterations in metabolism seen in the two barrel fields are not independent of each other, as one might expect from the whisker barrel circuit, but are a form of compensatory process dependent upon communication between the two hemispheres. Penicillin-induced focal seizures in rat motor cortex result in increased glucose utilization in ipsilateral and contralateral homotopic motor cortex (Collins, 1978). The pattern of increased glucose utilization within the contralateral motor cortex was described in that study as being similar to the pattern of the terminal fields of callosal connections. The barrel fields of the two cerebral hemispheres may be functionally connected via callosal pathways. Recent data have demonstrated vibrissae-related callosal connections in the rat which may enable this process to occur (Killackey et al., 1983).

One final factor to consider is that the 2-DG method is routinely utilized in the measurement of acute changes in the brain's capacity to process glucose. In contrast, the present findings indicate the establishment of a chronically altered state of increased glucose utilization within the ipsilateral barrel field in the presence of altered levels of sensory input. A recent study in mice utilizing an experimental design similar to the one in the present investigation demonstrated that the activities of several metabolic enzymes also increased over control levels in barrel fields associated with intact sets of whiskers (Dietrich et al., 1982). Taken together, these studies indicate that the level of regional functional activity as measured by glucose utilization can have profound effects on regulating the levels of various metabolic enzymes and therefore influencing metabolic processes within the relevant cells. Wong-Riley and Riley (1983) have recently demonstrated that if afferent impulse activity is blocked chemically, the level of cytochrome oxidase activity decreases in the affected postsynaptic neurons. Whether or not other biochemical-metabolic relationships exist within the central nervous sytem 


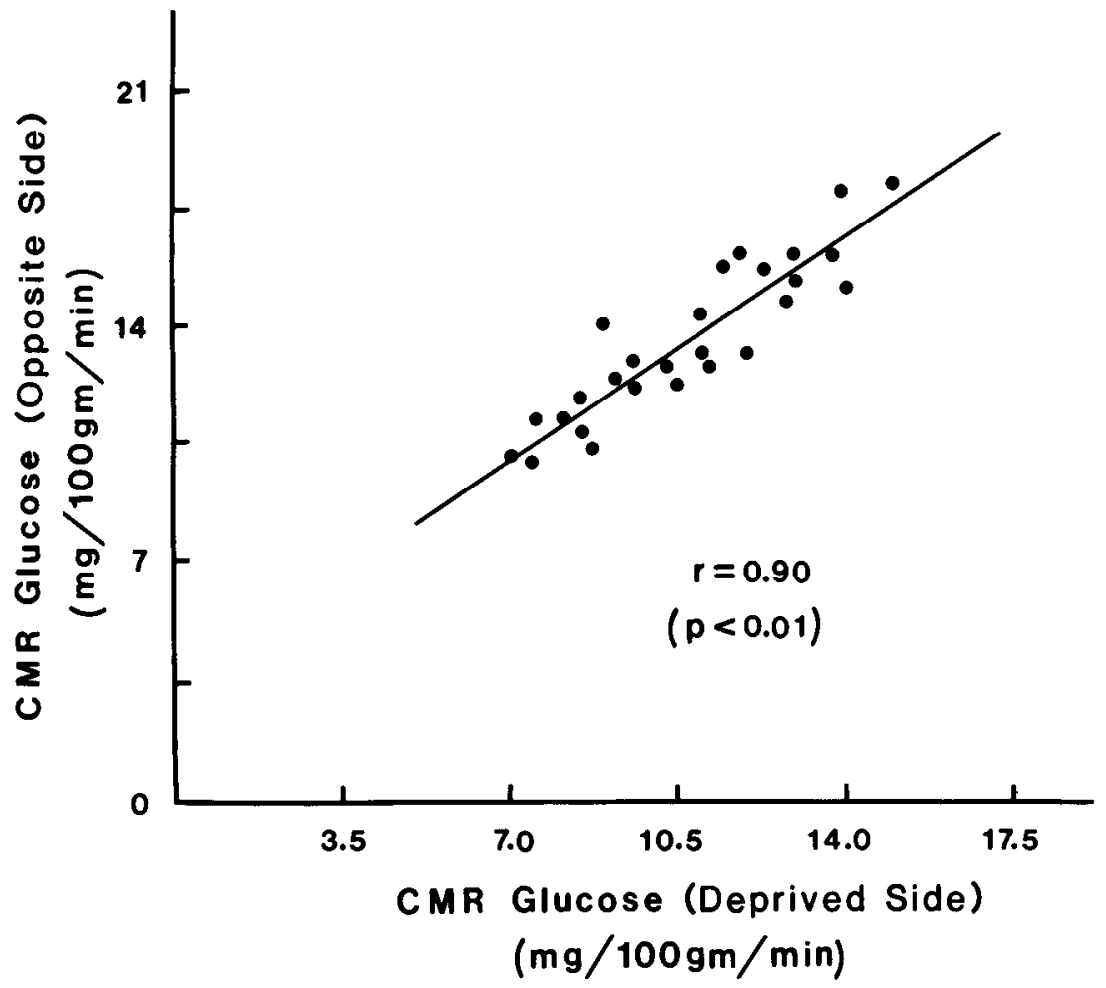

Figure 3. Interhemispheric relationship between average glucose utilization in deprived and opposite barrel fields following unilateral whisker cauterization. Each point represents a single animal. The line represents the least squares fit to the data: $y=0.95 x+3.41$ (correlation coefficient, $r$ $=0.90$ ).

which are responsible for brain functional heterogeneity may be determined by future studies.

The present findings provide metabolic evidence for cortical plasticity within the adult rat nervous system. The model utilized will allow for mechanisms of reorganization to be studied in greater detail. It is possible that mechanisms underlying recovery of function following more dramatic insults which, in contrast to peripheral deafferentation, result in cortical damage, may be similar to those at work in the present investigation. Further studies will expand upon these results and clarify the role and significance of the opposite hemisphere in neuronal processes and functional recovery.

\section{References}

Belford G. R., and H. P. Killackey (1979) Vibrissae representation in subcortical trigeminal centers in the neonatal rat. J. Comp. Neurol. 183: 305322.

Carlsson C., M. Hagerdal, and B. K. Siesjö (1975) Increase in cerebral oxygen uptake and blood flow in immobilization stress. Acta Physiol. Scand. 95: 206-208.

Collins, R. C. (1978) Use of cortical circuits during focal penicillin seizures: An autoradiographic study with (14C) deoxyglucose. Brain Res. 150: 487501.

Dietrich, W. D., D. Durham, O. H. Lowry, and T. A. Woolsey (1981) Quantitative histochemical effects of whisker damage on single identified cortical barrels in the adult mouse. J. Neurosci. 1: 929-935.

Dietrich, W. D., D. Durham, O. H. Lowry, and T. A. Woolsey (1982) "Increased" sensory stimulation leads to changes in energy-related enzymes in the brain. J. Neurosci. 2: 1608-1613.

Durham, D., and T. A. Woolsey (1978) Acute whisker removal reduces neuronal activity in barrels of mouse Sml cortex. J. Comp. Neurol. 178: 629-644.

Friedman, D. P., E. G. Jones, and H. Burton (1980) Representation pattern in the second somatic sensory area of the monkey cerebral cortex. $J$. Comp. Neurol. 192: 21-42.

Hand, P. J. (1981) The 2-deoxyglucose method. In Neuroanatomical TractTracing Methods, L. Heimer and M. J. Robards, eds., pp. 511-538, Plenum Press, New York.

Hand, P. J. (1982) Plasticity of the rat cortical system. In Changing Concepts of the Nervous System, A. R. Morrison and P. Strick, eds., pp. 49-68, Academic Press, Inc., New York.

Hand, P. J., R. R. Miselis, and M. Reivich (1977) A (14C)-2-deoxyglucose metabolic mapping study of the rat posteromedial barrel subfield. Soc. Neurosci. Abstr. 3: 483

Hubel D. H., T. N. Wiesel, and M. P. Stryker (1978) Anatomical demonstration of orientation columns in macaque monkey. J. Comp. Neurol. 177: 361380.

Ingvar, M., and B. K. Siesjö (1982) Effect of nitrous oxide on local cerebral glucose utilization in rats. J. Cerebr. Blood Flow Metab. 2: 481-486.

Jones, E. G., and T. P. S. Powell (1969) Connexions of the somatic sensory cortex of the rhesus monkey. I. Ipsilateral cortical connexions. Brain 92: 477-502.

Kaas, J. H., M. M. Merzenich, and H. P. Killackey (1983) The reorganization of somatosensory cortex following peripheral nerve damage in adult and developing mammals. Annu. Rev. Neurosci. 6: 325-356.

Kennedy, C., M. H. Des Rosiers, J. W. Jehle, M. Reivich, F. Sharp, and L. Sokoloff (1975) Mapping of functional neural pathways by autoradiographic survey of local metabolic rate with (14C)deoxyglucose. Science 187: 850-853.

Kennedy, C., M. H. Des Rosiers, O. Sakurada, M. Shinohara, M. Reivich, J. W. Jehle, and L. Sokoloff (1976) Metabolic mapping of the primary visual system of the monkey by means of the autoradiographic (14C) deoxyglucose technique. Proc. Natl. Acad. Sci. U. S. A. 73: 4230-4234.

Killackey, H., J. Olavarria, and R. C. Van Sluyters (1983) A vibrissae related pattern of callosal connections in the primary somatosensory cortex of the rat. Soc. Neurosci. Abstr. 9: 251.

Kirk, R. E. (1982) Multiple comparison tests. In Experimental Design: Procedures for the Behavioral Sciences, C. D. Laughton and M. E. Hill, eds., pp. 90-133, Brooks/Cole, Belmont.

McCulloch, J., H. E. Savaki, M. C. McCulloch, and L. Sokoloff (1979) Specific distribution of metabolic alterations in cerebral cortex following apomorphine administration. Nature 282: 303-305.

Merrill, E. G., and P. D. Wall (1978) Plasticity of connection in the adult nervous system. In Neuronal Plasticity, C. W. Cotman, ed., pp. 97-111, Raven Press, New York.

Merzenich, M. M., J. H. Kaas, J. Wall, R. J. Nelson, M. Sur, and D. Felleman (1983a) Topographic reorganization of somatosensory cortical areas 3b and 1 in adult monkeys following restricted deafferentation. Neuroscience 8: 33-55.

Merzenich, M. M., J. H. Kaas, J. T. Wall, M. Sur, R. J. Nelson, and D. J. Felleman (1983b) Progression of change following median nerve section in the cortical representation of the hand in areas $3 \mathrm{~b}$ and 1 in adult owl and squirrel monkcys. Neuroscience 10: 639665 .

Pulsinelli, W. A., D. E. Levy, and T. E. Duffy (1982) Regional cerebral blood 
flow and glucose metabolism following transient forebrain ischemia. Ann. Neurol. 11: 499-509.

Sharp, F. R., J. S. Kauer, and G. M. Shepherd (1975) Local sites of activityrelated glucose metabolism in rat olfactory bulb during olfactory stimulation. Brain Res. 98: 596-600.

Skeen, L. C. (1977) Odor-induced patterns of deoxyglucose consumption in the olfactory bulb of the tree shrew, Tupaia glis. Brain Res. 124: 147153.

Smith, C. B., C. Goochee, S. I. Rapoport, and L. Sokoloff (1980) Effects of ageing on local rates of cerebral glucose utilization in the rat. Brain 103: 351-365.

Sokoloff, L. (1975) Influence of functional activity on local cerebral glucose utilization. In Brain Work. The Coupling of Function, Metabolism and Blood Flow in the Brain. D. H. Ingvar and N. A. Lassen, eds., pp. 385-388, Academic Press, Munksgaard.

Sokoloff, L. (1977) Relation between physiological function and energy metabolism in the central nervous system. J. Neurochem. 29: 13-26.

Sokoloff, L. (1981) The deoxyglucose method for the measurement of local glucose utilization and the mapping of local functional activity in the central nervous system. Int. Rev. Neurobiol. 22: 287-333.

Sokoloff, L., M. Reivich, C. H. Kennedy, M. H. Des Rosiers, C. S. Patlak, K. D. Pettigrew, O. Sakurada, and M. Shinohara (1977) The (14C) deoxyglucose method for the measurement of local cerebral glucose utilization: Theory, procedure, and normal values in the conscious and anesthetized albino rat. J. Neurochem. 28: 897-916.

Van der Loos, H., and T. A. Woolsey (1973) Somatosensory cortex: Structural alterations following early injury to sense organs. Science 179: 395-398.

Van der Loos, $\mathrm{H}$. (1976) Barreloids in the mouse somatosensory thalamus. Neurosci. Lett. 2: 1-6.
Vincent, S. B. (1912) The function of the vibrissae in the behavior of the white rat. Behav. Monogr. 1: 7-85.

Waite, P. M. E., and P. K. Taylor (1978) Removal of whiskers in young rats causes functional changes in cerebral cortex. Nature 274: 600-602.

Wall, J. T., and C. G. Cusick (1984) Cutaneous responsiveness in primary somatosensory (S-I) handpaw cortex before and after partial handpaw deafferentation in adult rats. J. Neurosci. 4: 1499-1515.

Wall, P. D. (1977) The presence of ineffective synapses and the circumstances which unmask them. Philos. Trans. R. Soc. Lond. (Biol.) 278: 361-372.

Welker, C. (1971) Microelectrode delineation of fine grain somatotopic organization of Sml cerebral neocortex in albino rats. Brain Res. 26: 259275.

Welker, W. I. (1964) Analysis of sniffing of the albino rat. Behaviour 22: 223244.

Weller, W. L., and J. I. Johnson (1975) Barrels in cerebral cortex altered by receptor disruption in newborn, but not in five-day-old mice. Brain Res. 83: $504-508$

Wong-Riley, M., and D. A. Riley (1983) The effect of impulse blockage on cytochrome oxidase activity in the cat visual system. Brain Res. 261: 185193.

Wong-Riley, M. T. T., and C. Welt (1980) Histochemical changes in cytochrome oxidase of cortical barrels after vibrissal removal in neonatal and adult mice. Proc. Natl. Acad. Sci. U. S. A. 77: 2333-2337

Woolsey, T. A. (1978) Some anatomical bases of cortical somatotopic organization. Brain Behav. Evol. 15: 325-371.

Woolsey, T. A., and H. Van der Loos (1970) The structural organization of layer $\mathrm{IV}$ in the somatosensory region (SI) of mouse cerebral cortex. Brain Res. 17: 205-242. 